\author{
Military Technical College \\ Kobry El-Kobbah, \\ Cairo, Egypt.
}

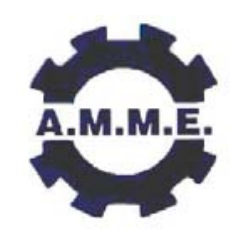

\title{
THE USING OF POLYURETHANE FOAMS INSIDE AIRCRAFT FUSELAGE AS ACOUSTIC INSULATION
}

$13^{\text {th }}$ International Conference
on Applied Mechanics and
Mechanical Engineering.

JURICKA ${ }^{*}$ M. and LAPCIK ${ }^{* *}$ L.Jr.

\begin{abstract}
The paper is focused on problematic of noise inside a fuselage of one propeller aeroplane. The aim of this paper is to analyse the noise produced by engine located in front of cabin for two passengers and also to show an application of specific polyurethane as an insulation layer. There were a sound absorption coefficient; a sound reflection coefficient and a sound pressure level are the most important of acoustic values. The measurements were made in laboratory and in aeroplane. The final interpretation depends on test results.
\end{abstract}

\section{KEY WORDS}

Noise, frequency, sound absorption coefficient, sound reflection coefficient, sound pressure level

* Graduate student, Department of Physics and Material Engineering, Tomas Bata University in Zlin, Czech Republic.

** Professor, Department of Physics and Material Engineering, Tomas Bata University in Zlin, Czech Republic. 


\section{INTRODUCTION}

Sound is such a common part of everyday life that we rarely appreciate all of its functions. It provides enjoyable experiences such as listening to music or the singing of birds. Many sounds are unpleasant or unwanted - these are called noise. However, the level of annoyance depends not only on the quality of the sound, but also our attitude towards it. The sound of his new jet aircraft taking off may be music to the ears of the design engineer, but will be ear-splitting agony for the people living near the end of the runway $[1,2]$.

\section{THEORY}

There was used a special material based on polyurethane for experimental part of measurement. This polyurethane has good acoustic properties and it is especially self extinguishing. The material has to be excellent for a sound absorption coefficient and acoustic pressure. The material is called $53535 \mathrm{~F}$ and it is designed as series product. The basic tensile properties are shown in Tab. 1. and 2. The acoustic energy separate inside material is show in Fig. 1.

Other samples S20 and S30 were called as well as sample S10. The symbol a, b means that a-absorption coefficient and b-reflection coefficient. The RPM 2000 was acoustic pressure without insulation; 2000-i was acoustic pressure with use insulation.

The sound absorption coefficient $\alpha$ is defined as relation:

$$
\alpha=\frac{I_{2}}{I_{0}}[-]
$$

The result is non-dimensional value in the interval between 0 and 1 [4].

The same is defining sound reflected coefficient $\beta$ :

$$
\begin{aligned}
& \beta=\frac{I_{1}}{I_{0}}[-] \\
& \alpha+\beta=1[-]
\end{aligned}
$$

One of important values id sound pressure level that is defined:

$$
L_{p}=20 . \log \frac{p}{p_{0}}[\mathrm{~dB}]
$$

where $p$ is effective value of sound pressure level, $p_{0}$ is reference value of sound pressure level [3]. 


\section{EXPERIMENT}

Measurement in laboratory - the measurement is created in laboratory and in practice part. In the laboratory conditions are measurement sound absorption coefficient and sound reflection coefficient. The both values are measured in Kund's tube - type 4206 produced by Bruel \& Kjær. The impedance tube is linked to multifunction analyzer PULSE - type 3560-B-030 and with amplifier - type 2706 for measurement sound absorption coefficient and sound reflection coefficient. The devices are show in Pic. 1.

Practice measurement - for the practice measurement was used device for analyse sound pressure level produced by Bruel \& Kjær - type 2146. Most important was selected of mode flight. The location microphone with B\&K 2146 inside fuselage of aero plane was in the middle of cabin for two passengers. There were measured modes standing, take off and flight. The results were shoes in graphs as different between using insulation and without used insulation. The picture number 3 . show type of ultralight aero plane SportStar produced by Evektor Kunovice - Czech Republic. The Fig. 3. shows layer of insulation based on polyurethane. The parts of polyurethane were bonded between parts of construction and the Fig. 4. show device for measurement sound pressure level - analyzer B\&K type 2146 and microphone B\&K type 4190.

Figures 6 and 7 show sound absorption and reflection coefficient for variety of thicknesses 10, 20 and $30 \mathrm{~mm}$. Every sample was measured with air space for both coefficients. The space area is for every sample 10,20 and $30 \mathrm{~mm}$.

The practice measuring was realized inside fuselage of aero plane SportStar. The modes were standing, take off and flight. The substance of graphs is different between curve of insulation and stand of without insulation. For the standing were used modes of 2000, 3000 and 4000 RPM. For the taking off were measured modes of 5000 RPM and for the flight were used modes of 3000, 4000 and 5000 RPM.

The tables of data obtained in tests for measurement sound pressure level are show in the next table. The value is calling total sound pressure level (SPL) for selected modes - standing, take off and flight $[4,5]$.

\section{CONCLUSION}

The results of measurements show good properties of polyurethane as an insulation layer inside fuselage in aeroplane. The values of sound absorption coefficient, sound reflection coefficient and sound pressure level are shown in the graphs. The graphs show effective values for using of polyurethane type S3535F inside fuselage of ultra light SportStar.

The sound absorption coefficient shows that the values are effective for the frequency range at intervals $500 \mathrm{~Hz}-2000 \mathrm{~Hz}$. The best of absorption coefficient is for The thickness $30 \mathrm{~mm}$ (S30) is the best measured value of sound absorption coefficient. Maximal frequency values were measured for:

$$
\begin{aligned}
& \mathrm{S} 10 \mathrm{a}-1=1662 \mathrm{~Hz} / \alpha=0,99 ; \\
& \mathrm{S} 20 \mathrm{a}=1400 \mathrm{~Hz} / \alpha=0,85 ; \\
& \text { S30a-2 = } 1388 \mathrm{~Hz} / \alpha=0,87 .
\end{aligned}
$$


There were measured these effective values of thicknesses for the reflection coefficient:

$$
\begin{aligned}
& \text { S10b-1 = } 1654 \mathrm{~Hz} / \beta=0,01 ; \\
& \text { S20b-3 = } 1392 \mathrm{~Hz} / \beta=0,16 ; \\
& \text { S30b-2 = } 1388 \mathrm{~Hz} / \beta=0,13 .
\end{aligned}
$$

The most important values are the data measured in the fuselage of aero plane in different modes. There were used different parts of polyurethane in the wall of fuselage. The data were measured with and without using of insulation. The differences between modes are shown in tables 3,4 and 5. The average differences of modes are around 6 $\mathrm{dB}$ and the frequency ranges for effective values are at intervals $10 \mathrm{~Hz}-1500 \mathrm{~Hz}$. There was used weight filter type $A$ for the measuring of sound pressure level and the frequency range was at intervals $1 \mathrm{~Hz}-20000 \mathrm{~Hz}$.

\section{ACKNOWLEDGEMENT}

Very thanks for company Evektor Kunovice a.s. and thanks for Mr. Petr Javorsky for measurement inside aero plane SportStar.

\section{REFERENCES}

[1] NOVY, R., Hluk a chveni, CVUT Praha, ISBN 80-01-02246-3, (2000).

[2] MISUN, V., Vibrace a hluk, PC-DIR Brno, ISBN 80-214-1262-3 (1998).

[3] MADEJEWSKI, B., Aeroakustika, zaklady teorie a aplikace na konstrukci letadel, VUT Brno, ISBN 55-587/1-86 (1986).

[4] SMETANA, C., Mereni a hodnoceni, Praha - Sdel. technika, ISBN 80-901936-25 (1998).

[5] TUMA, J., Zpracovani signalu ziskanych z mechanickych systemu uzitim FFT, Praha - Sdel. technika, ISBN 80-901936-1-7 (1997).

[6] KOEPNICK, J., Photo of author - EVEKTOR Aerotechnik, online: http://www.evektor.cz/at/en/gallery.html

\section{TABLES AND FIGURES}

Table 1. Tensile properties PUR - S3535F

\begin{tabular}{|c|c|c|c|c|c|}
\hline Sample & $\begin{array}{c}\Delta \mathrm{l} \\
(\mathrm{m})\end{array}$ & $\begin{array}{c}\mathrm{F} \\
(\mathrm{N})\end{array}$ & $\begin{array}{c}\sigma_{\max } \\
(\mathrm{MPa})\end{array}$ & $\varepsilon(\%)$ & $\begin{array}{c}\mathrm{E} \\
(\mathrm{MPa})\end{array}$ \\
\hline S3535F & 192 & 19 & 0,19 & 166 & 0,2 \\
\hline
\end{tabular}

Table 2. Names of samples in graphs

\begin{tabular}{|c|c|}
\hline Symbol & Sample \\
\hline S10 & Sample S10 without air space \\
\hline S10-1 & S10 with air space $-1 \mathrm{~cm}$ \\
\hline S10-2 & S10 with air space $-2 \mathrm{~cm}$ \\
\hline S10-3 & S10 with air space $-3 \mathrm{~cm}$ \\
\hline
\end{tabular}


Table 3. Total SPL - standing

\begin{tabular}{|r|c|c|c|}
\hline RPM & $\mathbf{4 0 0 0}$ & $\mathbf{3 0 0 0}$ & $\mathbf{2 0 0 0}$ \\
\hline $\mathrm{L}(\mathrm{dB})$ & 106,8 & 104,3 & 104,4 \\
\hline $\mathrm{L}(\mathrm{dB})-\mathrm{i}$ & 98,8 & 100,3 & 97,1 \\
\hline$\Delta \mathrm{L}(\mathrm{dB})$ & $\mathbf{8}$ & $\mathbf{4}$ & $\mathbf{7 , 3}$ \\
\hline
\end{tabular}

Table 4. Total SPL - take off

\begin{tabular}{|c|c|}
\hline RPM & $\mathbf{5 0 0 0}$ \\
\hline $\mathrm{L}(\mathrm{dB})$ & 107,1 \\
\hline $\mathrm{L}(\mathrm{dB})-\mathrm{i}$ & 100,7 \\
\hline$\Delta \mathrm{L}(\mathrm{dB})$ & $\mathbf{6 , 4}$ \\
\hline
\end{tabular}

Table 5. Total SPL - flight

\begin{tabular}{|r|c|c|c|}
\hline RPM & $\mathbf{5 0 0 0}$ & $\mathbf{4 0 0 0}$ & $\mathbf{3 0 0 0}$ \\
\hline $\mathrm{L}(\mathrm{dB})$ & 106,9 & 106,8 & 105,5 \\
\hline $\mathrm{L}(\mathrm{dB})-\mathrm{i}$ & 100,3 & 99,2 & 98,1 \\
\hline$\Delta \mathrm{L}(\mathrm{dB})$ & $\mathbf{6 , 6}$ & $\mathbf{7 , 6}$ & $\mathbf{7 , 4}$ \\
\hline
\end{tabular}
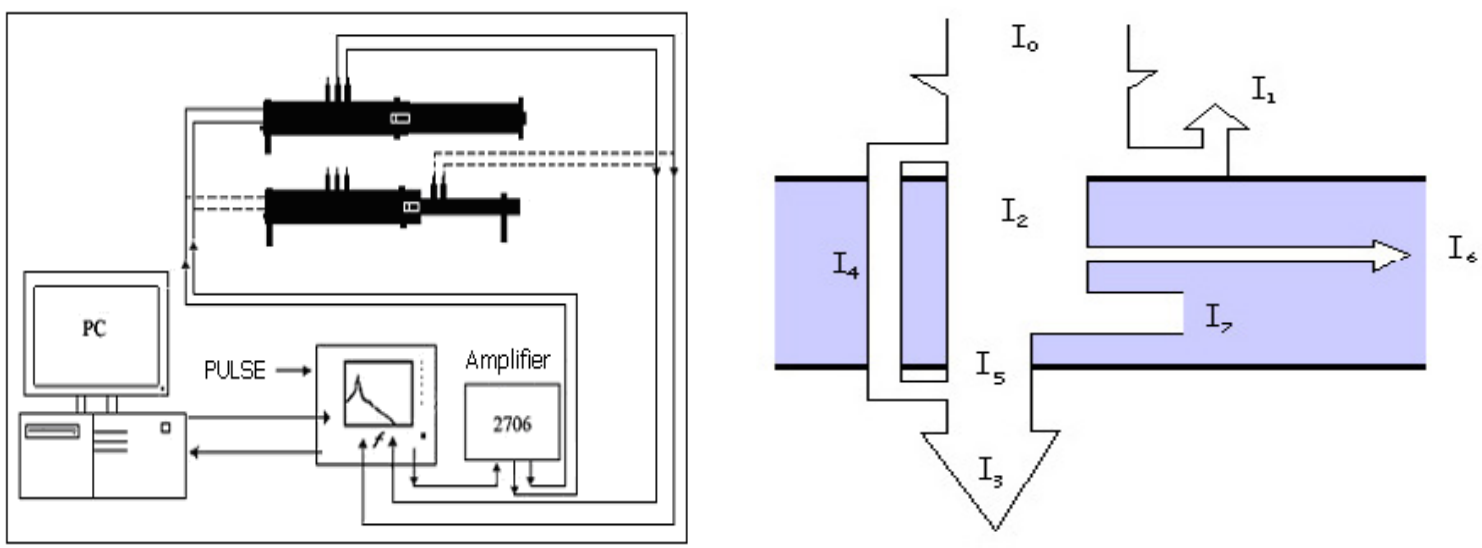

Fig.1. Schema of the setup and acoustic energy in material [1]

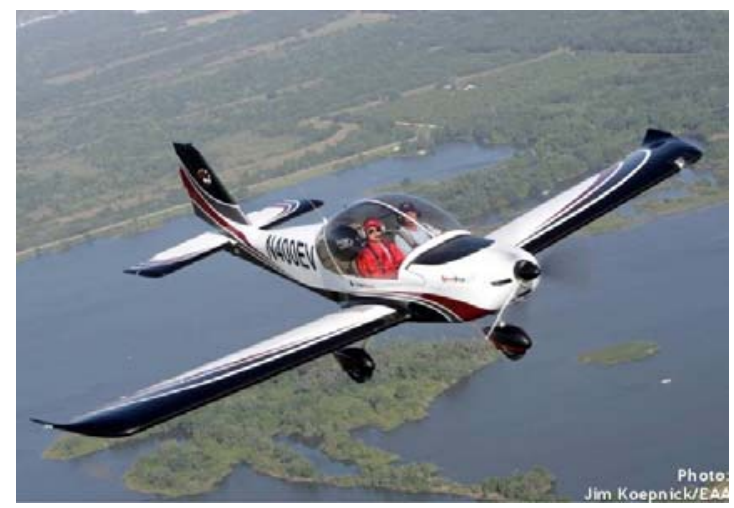

Fig.2. SportStar [6] 

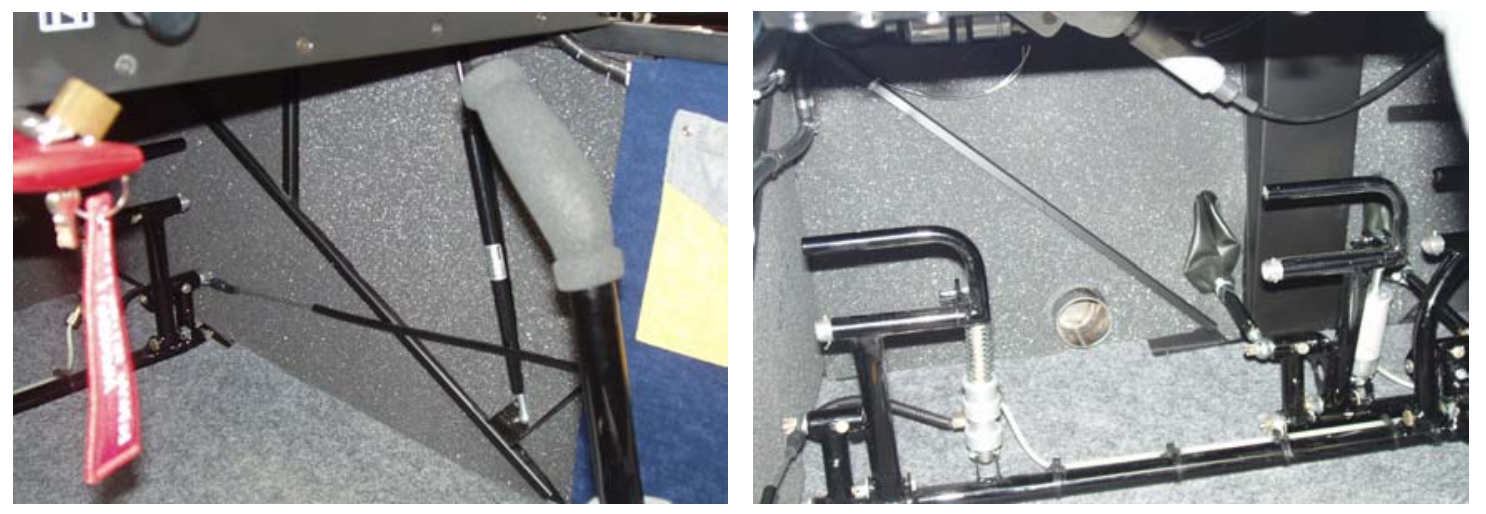

Fig.3. Insulation layer

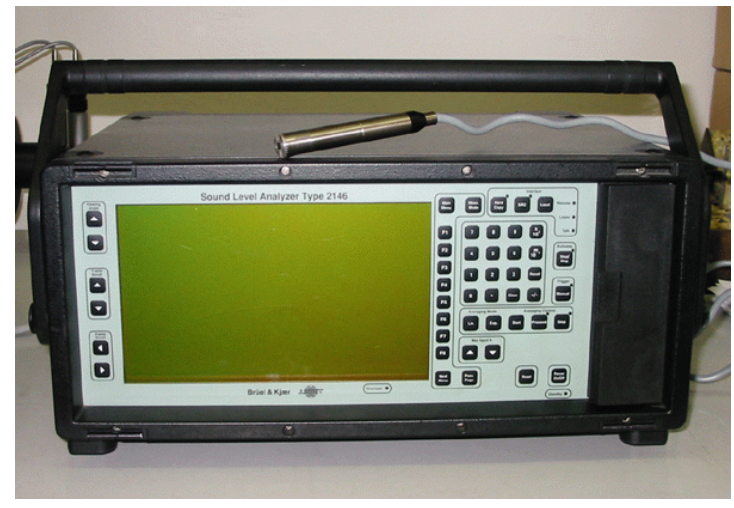

Fig.4. Analyzer type B\&K 2146 [1]

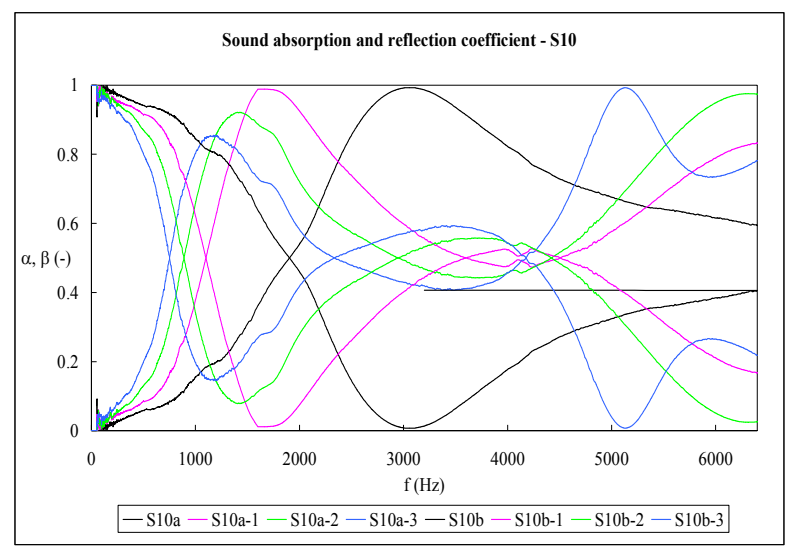

Fig.6. Sound absorption and reflection coefficient - sample S10 

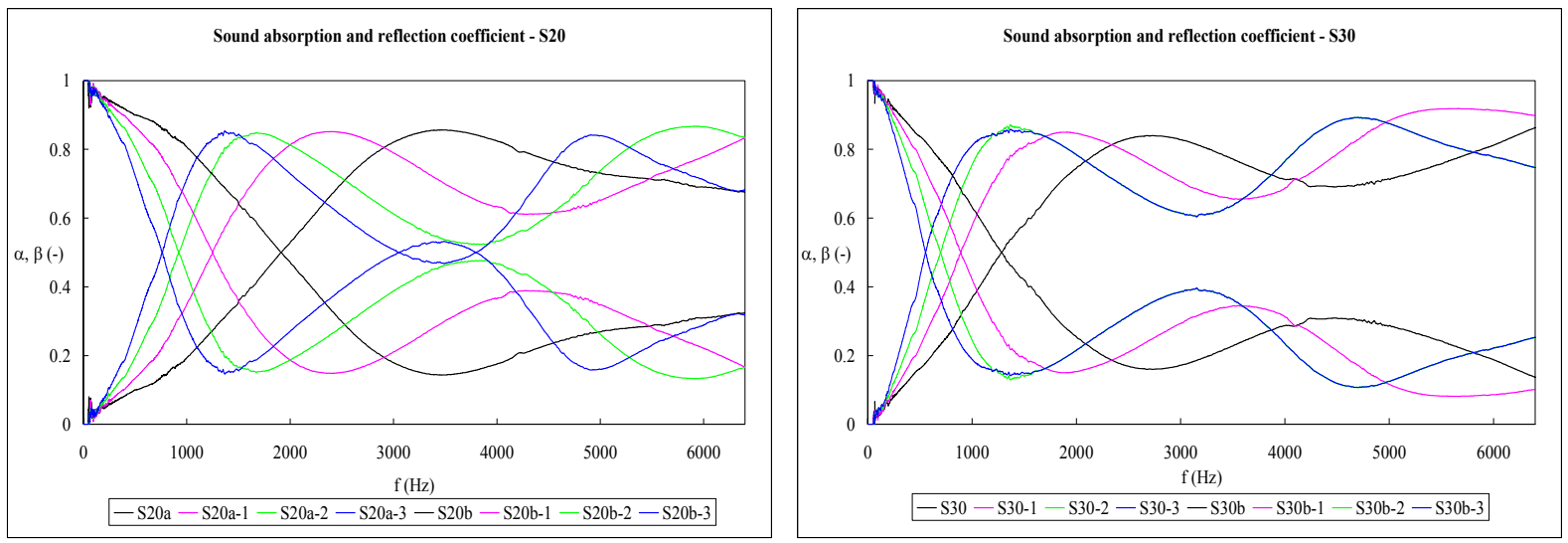

Fig.7. Sound absorption and reflection coefficient samples S20 and S30
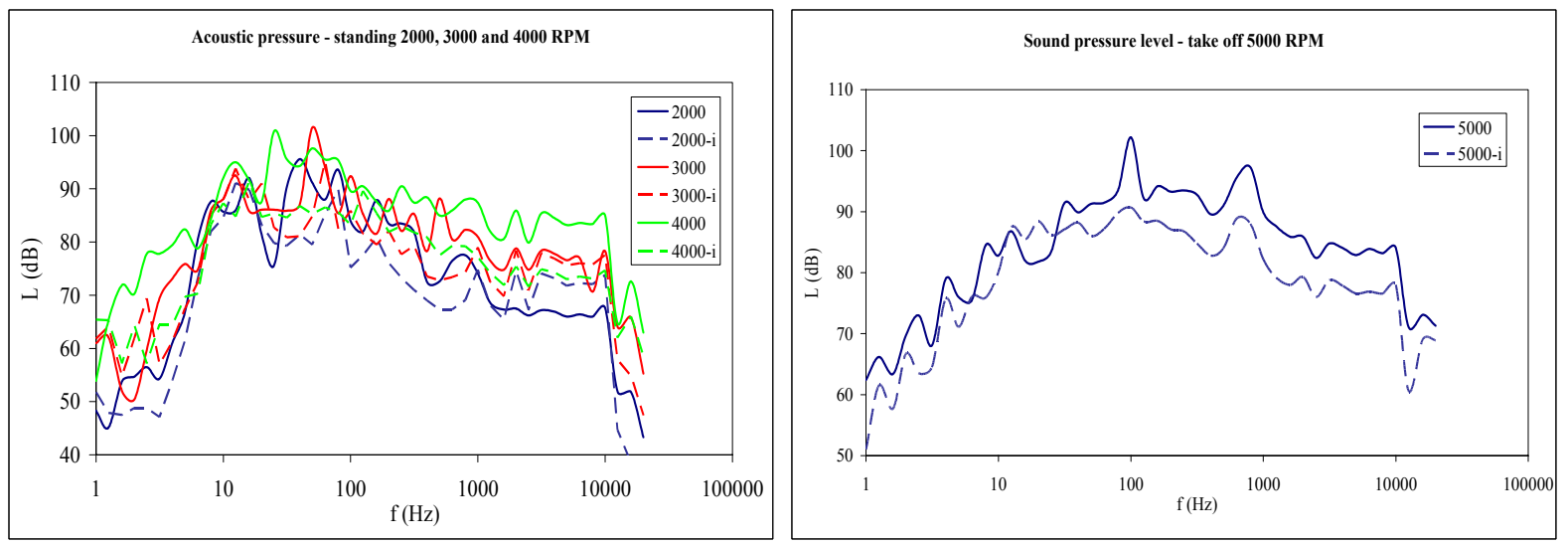

Fig.8. SPL - standing and take off

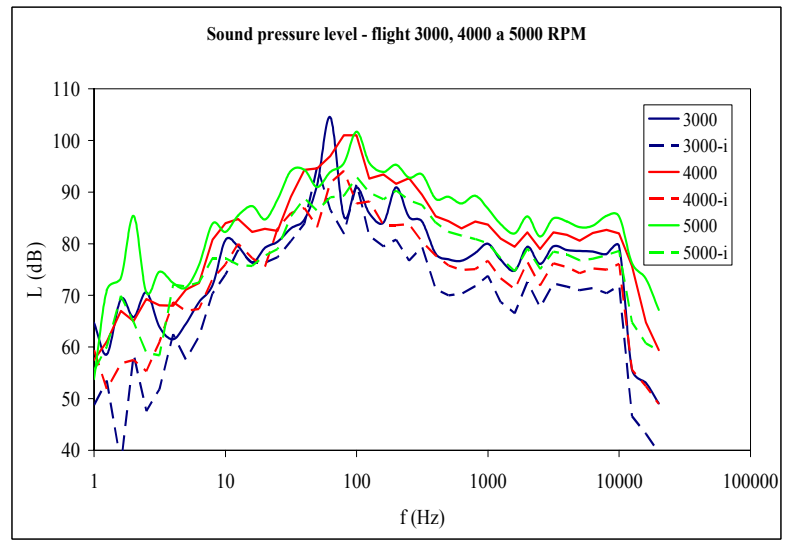

Fig.9. SPL - flight 